BMJ Open Sport \& Exercise Medicine

\section{Beighton scoring of joint laxity and injury incidence in Middle Eastern male youth athletes: a cohort study}

\begin{abstract}
To cite: Rejeb A, Fourchet F, Materne 0 , et al. Beighton scoring of joint laxity and injury incidence in Middle Eastern male youth athletes: a cohort study. BMJ Open Sport \& Exercise Medicine 2019;5:e000482. doi:10.1136/ bmjsem-2018-000482
\end{abstract}

Accepted 31 December 2018

Check for updates

\section{(c) Author(s) (or their} employer(s)) 2019. Re-use permitted under CC BY-NC. No commercial re-use. See rights and permissions. Published by BMJ.

${ }^{1}$ Aspetar Orthopaedic and Sports Medicine Hospital, Doha, Qatar 2Department of Rehabilitation Sciences and Physiotherapy, Ghent University, Ghent, Belgium ${ }^{3}$ Hopital de la Tour, Meyrin, Switzerland

Correspondence to Abdallah Rejeb; abdallah.rajeb@ aspetar.com

\section{ABSTRACT}

Objectives To examine the association between generalised joint laxity (GJL) and injury rates in Middle Eastern male youth athletes.

Design Prospective observational study consisting of GJL screen and injury audit (season 2009/2010).

Setting Aspire Sports Academy Doha, Qatar.

Participants A total of 226 adolescent male athletes (mean age: 14.2 years; SD: 1.7; range: $10-18$ ) involved in 15 sporting activities were grouped into contact and noncontact sports. All available athletes were included in this study.

Outcome measures A seasonal injury audit, athletes' anthropometric characteristics, for example, weight, height and body mass index and screen for GJL to determine Beighton Score (BS).

Results The 226 athletes sustained 596 injuries and $75 \%$ reported at least one injury over a seasonal injury audit. Players in contact sports were injured more often than players in non-contact sports (more frequent injuries than injury-free time in contact sports; 127 days $(95 \% \mathrm{Cl}$ 93 to 160$)$ vs 176 days in non-contact sports $(95 \% \mathrm{Cl} 118$ to 234$)(p<0.001)$. Survival analysis showed that gradient BS was not associated with injury $\mathrm{HR}=1.004(95 \% \mathrm{Cl} 0.95$ to 1.06) in the overall cohort. However, BS was associated with a greater injury risk in contact sports (HR: 1.29; $95 \% \mathrm{Cl} 1.05$ to $1.59 ; p=0.015$ ).

Conclusion Greater GJL, defined by gradient BS, plus involvement in contact sports together influence injury risk in youth athletes. Preseason documentation of GJL scoring should be considered specifically for contact sports as injury pre-emptive measure.

\section{INTRODUCTION}

Clinicians have variably described both a lack of generalised flexibility ('stiffness') and an increase in generalised joint laxity (GJL) ('hyperlaxity') as being intrinsic risk factors for injury. ${ }^{1}$ It is unusual, however, for a clinician to be able to ascribe an exact definition of such increased or decreased flexibility, and particularly at what point this variation from normal becomes pathognomonic. A better understanding of this relation would facilitate the development of an injury profile index to assist in directing athletes into sports where
What is already known about the subject?

Joint laxity is associated with increased risk of knee (but not ankle) injury for athletes.

- There are no data for how laxity is associated with for other joint injuries for contact/non-contact athletes.

What this study adds to existing knowledge?

Joint laxity increases adolescent athlete injury risk but only for participants in contact sports.

- The effect size ( $\mathrm{HR} 1.29 ; 95 \% \mathrm{Cl} 1.05$ to 1.59 $\mathrm{p}=0.015$ ) warrants its inclusion in screening procedures and during clinical examination of adolescent athletes.

their individual traits are protective and beneficial, rather than detrimental. ${ }^{2}$ Typically, in clinical practice, GJL is quantified through use of the Beighton classification system comprising scoring of nine individual tests of movement on a dichotomous ( $1=$ yes, $0=$ no) score for a maximum of nine points (ie, Beighton Score (BS)). ${ }^{3}$ Previous work ${ }^{5}$ has suggested the usefulness of defining a clinical cut-off point of $4 / 9$ instead of considering the score to be linearly related to injury risk; however, this definition remains debated. ${ }^{6}$

Clinicians and coaches have described GJL to be either beneficial or disadvantageous to sporting performance and injury risk according to the sport being examined. For instance, it is unusual for any athlete to reach international standards in female gymnastics without being defined as hypermobile in the Beighton Classification. ${ }^{7}$ Conversely, some authors argue that GJL was a predisposing factor to injuries, ${ }^{89}$ and subjects with such GJL should therefore be recommended against participation in sports that involve heavy physical contact or the risk of falls which might likely lead to injury. While the data is scarce, some research suggests hyperlaxity as a risk factor for injury in adolescents 
and others. ${ }^{10}$ There is a paucity of high-quality reports to backup these widely held beliefs as reported in a recent systematic review and meta-analysis showing GJL to increase the odds of knee but not ankle injury, and no data on injury to the foot, hip, spine or upper limb. ${ }^{1}$ Further, this review concluded that there was insufficient data to examine the interaction of sporting participation (eg, contact vs non-contact sports). ${ }^{1}$

The prevalence of GJL varies with gender and ethnicity. ${ }^{3711}$ To gather useful information regarding the post-test odds of any potential risk factor's interaction with GJL, it is critical to document the pretest incidence, that is the prevalence of GJL in the population of interest. ${ }^{12} 13$

Current understanding of the prevalence and descriptive epidemiology of GJL in childhood is limited, making it difficult to draw clear conclusions about causal pathways. Also the extent to which GJL is associated with injury is unclear. ${ }^{14}$

Therefore, the aim of this study was to evaluate the relationships between GJL (BS) on the risk of injury among youth athletes engaged in different sports activities.

\section{METHODS}

\section{Study design and settings}

Prospective cohort study design at the Aspire Academy of Sports, Doha, State of Qatar. Study took place during the 2009/2010 academic season with a follow-up period of 9 months.

\section{Participants}

Participants were full-time registered adolescent athletes at Aspire Academy for Sports, Doha, State of Qatar. Athletes included in the study were all male, aged 10-18 years (average age 14.2 \pm 1.7 years) and screened for GJL.

All 226 participants met the inclusion criteria and were involved in 15 different sport activities: football $(n=125)$, track and field $(n=35)$, fencing $(n=8)$, gymnastics $(n=6)$, swimming and diving $(n=6)$, table tennis $(n=6)$, tennis $(n=7)$, Tae kwon do $(n=2)$, judo $(n=5)$, squash $(n=10)$, shooting $(n=4)$, golf $(n=5)$, rowing $(n=2)$, multi $(n=1)$ and sailing $(n=2)$. The sport disciplines were grouped into two categories: contact $(\mathrm{n}=132)$ and non-contact sports $(\mathrm{n}=94)$.

Parental consent and child's assent were obtained for all measurements.

\section{Injury definition and data collection}

An injury was defined as a physical complaint, which occurred during sports training, strength and conditioning training or during competition. A traumatic injury was defined as an injury resulting from a specific and identifiable mechanism, including contact and non-contact circumstances with acute onset. Overuse injuries were defined as injuries resulting from insidious onset without a recognisable mechanism. ${ }^{15}$

All injuries were collected by two physical therapists. Data from medical records were used to document all sports-related injuries during the study. Each sporting

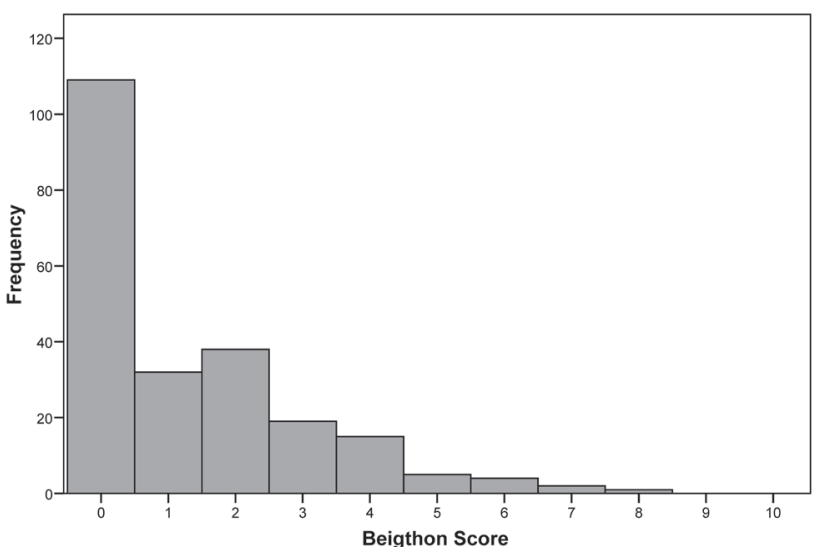

Figure 1 Frequency histogram for the entire cohort of student athletes classified by Beighton Score.

discipline had a dedicated full-time physiotherapist and a full-time employed medical doctor at the sports academy. The medical record used an injury reporting system based on the football injury reporting system ${ }^{16}$ and the Sport Medicine Diagnostic Coding System. ${ }^{17}$ Information was gathered concerning all injuries related to sports activity, including several related variables (eg, type, location, affected structure, mechanism (acute vs overuse)) by clinician. Injury severity was defined, based on days of absence from usual sport participation, as slight (1 day or less), minimal (2-3 days), mild (4-7 days), moderately serious ( $8-28$ days), serious ( $>28$ days up to 6 months) or long-term ( $>6$ months). ${ }^{18}$

\section{Measurement of GJL}

GJL was assessed by two trained measurers or physiotherapists (AR and JH). We used $20 \mathrm{~cm}$ and $30 \mathrm{~cm}$ goniometers. Reporting of the joint range at the thumbs, fifth fingers, knees, elbows and spine were after the methods initially described by Beighton and Horan. ${ }^{3} 19$ The tests were done with the athletes standing, except for the knee extension test measured with the subject supine. All tests were performed bilaterally, except for trunk flexion. Each positive test marked 1 point for a total score of $0-9$. The BS was recorded first as an absolute score, and later analysed in the clinical classifications of cut-offs: $0-2,3-5$ and $>5 ;{ }^{5} 0-4$ and $>4 ; 0,1-5$ and $\geq 6$ (figure 1 ).

\section{Anthropometric measures}

At the sports science unit of the academy, height was measured to the last complete millimetre, using a Harpenden stadiometer. Weight was measured to the nearest 50 gm using a body fat analyser (model TBF 305; Tanita). Body mass index (BMI) was calculated as $\mathrm{kg} / \mathrm{m}^{2}$ and subjects were categorised as underweight (BMI 18.5), ideal weight (BMI 18.5-24.9), overweight (BMI 25-29.9) or obese (BMI $\geq 30$ ) based on standard definitions.

\section{Statistical analysis}

Statistical analyses were performed with the use of SPSS V.19.0. The Student's t-test was used to compare mean values of normally distributed data (age, height, weight 
and $\mathrm{BMI}) \cdot \chi^{2}$ test was used to compare categorical variables in non-injured athletes versus athletes injured at least once. Data were analysed comparing KaplanMeier survival estimates by using the Breslow statistic. Curves were compared with the Breslow statistic based on dependent factor BS group stratified by sports category (contact and non-contact) to determine if GJL was associated with injury incidence, thus adjusting sports category as potential effect modifier. Median injury-free survival time and $95 \%$ CI were calculated. For the above analysis, only first injury per player was counted. In addition, subsequent survival analyses were carried out in STATA V.11.0. A stratified Cox proportional hazard model that stratifies order of recurrent injuries after adjusting the variances of HRs among recurrent events on the same subjects was performed using marginal Prentice, Williams and Peterson counting process method ${ }^{20}$ to further explore the temporal effect of GJL on recurrent events. HRs and 95\% CI were calculated. As the incidence of GJL was unknown in Middle Eastern Arabic populations, the assumption was made that the incidence was similar to Caucasians, and thus a preliminary power analysis suggests that to detect an effect of GJL on injury at $\mathrm{p}=0.05$, approximately 200 subjects would be required (for an effect size of 0.1 ). $P$ value $\leq 0.05$ was used to define statistical significance.

\section{Patient and public involvement statement}

Patients and public were not involved in the analysis of this study.

\section{RESULTS}

In this cohort ( $\mathrm{N}=226)$, contact sports (football, judo and tae kwon do) represented 58\% ( $\mathrm{n}=132)$ and non-contact sports (track and field and other sports) represented $42 \%(\mathrm{n}=94)$.

The prevalence of GJL, as defined using a BS cut-off of $\geq 6$ was only $3.1 \%$ and the subgroup of $1-5$ was $48.2 \%$. Figure 2 shows the distribution of GJL across all study groups.

Out of the 226 athletes, a total of 596 injuries were identified and $74.8 \%$ reported with at least one injury over a seasonal injury audit. Table 1 shows the characteristics of non-injured athletes and injured athletes. No significance associations found between injured and un-injured for anthropometric indexes (height, weight and BMI).

Across all sports, $81.6 \%$ of football participants presented with at least one injury. The prevalence of injuries in contact sports is significantly higher compared with non-contact sports $(81.8 \%$ vs $64.9 \%, \mathrm{p}=0.004)$.

Contact sports had a lower injury-free survival time compared with non-contact sports; 127 days (95\% CI 93 to 160 ) versus 176 days (95\% CI 118 to 234$)$ ( $\mathrm{p}<0.001)$. Kaplan-Meier Survival analysis estimates showed that median injury-free survival time for contact sport athletes was greater among BS of 0 athletes (148 days (95\% CI 121 to 176)) compared with those with BS 1-5 (90 days (95\% CI 81 to $98, \mathrm{p}=0.022)$ ).

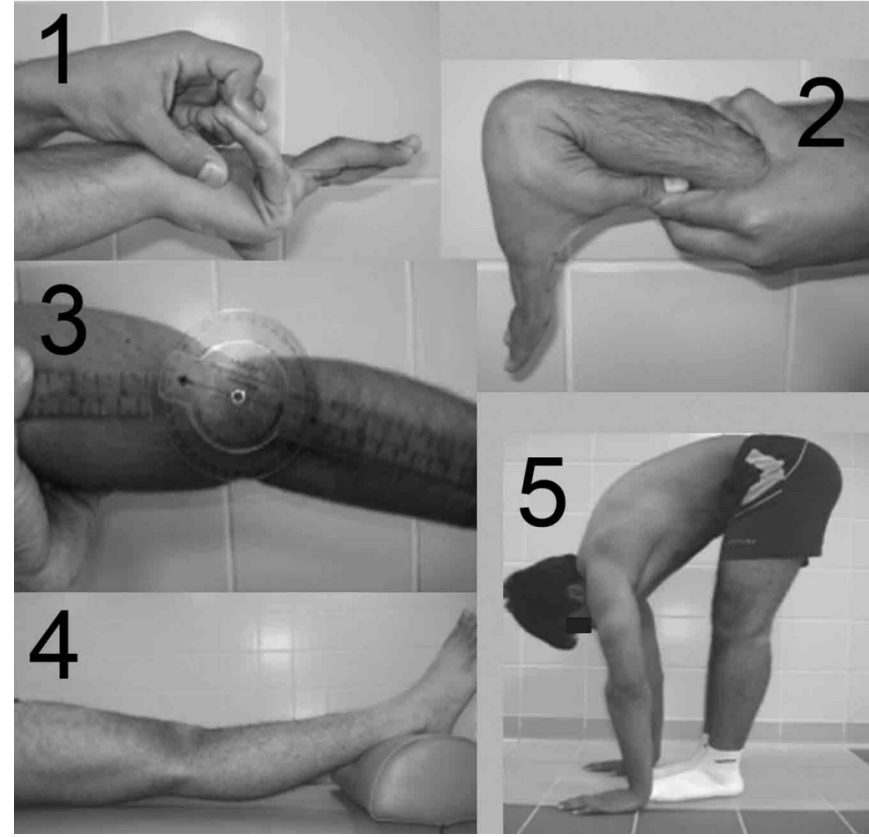

Figure 2 Beighton Scoring system. (1) Little finger passive dorsiflexion beyond $90^{\circ}$. (2) Thumb passive dorsiflexion to the flexor aspect of the forearm. (3) Elbow hyperextension beyond $10^{\circ}$. (4) Knee hyperextension beyond $10^{\circ}$. (5) Palms and hands can rest flat on the floor.

A gradient of Beighton scoring was associated with an increased risk of injury (HR 1.29; 95\% CI 1.05 to 1.59, $\mathrm{p}=0.015)$, but no significant association was established between injury severity and Beighton scoring cut-off (0 and 1-5) $(\mathrm{p}=0.12)$.

\section{DISCUSSION}

GJL was associated with injury risk in contact, but not in non-contact sports. This concurs with the findings of Konopinski $e t a l^{11}$ who found an increased incidence of injuries in hypermobile football players (22 vs 6 per 1000 hours of exposure). In contrast, our results failed to find an increased injury severity in the hypermobile players as documented by Konopinski et al. ${ }^{21}$

Our data analysis in reference to the three commonly used subgrouping classification methods showed a non-significant difference in individual injury risk between the hypermobile athletes and similar injury rates in both the hypermobile and non-hypermobile participants in the complete cohort which concur with the results of Collinge and Simmonds. ${ }^{5}$ The distribution of scores in this group is skewed towards a score of 0 . Due to the small number of athletes with $B S \geq 6 \quad(n=7)$, a meaningful estimate of risk in this category could not be ascertained. In a study, ${ }^{5}$ the prevalence of hypermobility was $33.3 \%$, with $\mathrm{BS} \geq 4$ or more; this result is not in line with the results of our study where the prevalence was only $3.1 \%$, with $\mathrm{BS} \geq 6$. This discrepancy could be explained by the variation of cut-offs of GJL scoring, although BS with cut-off $\geq 6$ is recommended for clinical use. ${ }^{21}$ 
Table 1 Characteristics of injured versus non-injured athletes

\begin{tabular}{|c|c|c|c|c|c|}
\hline Variables & & $\mathbf{N}$ & Not injured n (\%) & Injured $^{\dagger} \mathrm{n}(\%)$ & $P$ value \\
\hline \multirow[t]{2}{*}{ Demographics } & Participants & 226 & $57(25.2)$ & $169(74.8)$ & \\
\hline & Age (years)* & 219 & $13.6 \pm 2.0,14.0$ & $14.4 \pm 1.6,15.0$ & 0.005 \\
\hline \multirow[t]{4}{*}{ Anthropometric data } & Height $(\mathrm{cm})^{\star}$ & 98 & $156.0 \pm 10.2,155.0$ & $160.9 \pm 13.1,160.9$ & 0.147 \\
\hline & Weight $(\mathrm{kg})^{*}$ & 98 & $45.3 \pm 11.5,42.7$ & $50.0 \pm 12.5,48.7$ & 0.158 \\
\hline & Body mass index & 98 & $18.3 \pm 2.5,18.3$ & $19.2 \pm 4.4,18.5$ & 0.492 \\
\hline & Beighton Score* & 226 & $1.2 \pm 1.7,0$ & $1.3 \pm 1.7,1$ & 0.482 \\
\hline \multirow{2}{*}{$\begin{array}{l}\text { Contact versus non- } \\
\text { contact }\end{array}$} & Contact & 132 & 24 (18.2) & $108(81.8)$ & 0.004 \\
\hline & Non-contact & 94 & $33(35.1)$ & $61(64.9)$ & \\
\hline
\end{tabular}

${ }^{*}$ All score variables were presented as mean $\pm S D$, median.

${ }^{\dagger}$ Injured once or more.

Our data showed a high prevalence of injury in footballers $(81.6 \%)$ which extended the findings of Ristolainen et $a l^{22}(73.4 \%)$. Given this relatively high prevalence, we recommend the clinical utility of Beighton screening in this category of athletes.

Previous authors have used Poisson counts and injury incidence rates $^{21}$; however, we have analysed the data after the methods of Ullah et $a l^{23}$ employing survival analysis Cox proportional hazards models that address variances of parameter estimates of recurrent injuries of same subjects.

While this research has documented an association between hyperlaxity and injury likelihood in contact sports, it is not possible to ascribe causation, and the possibility remains that athletes choose sports in some part due to their inherent joint laxity.

Our study of multisport analysis is in-line with the research of Nathan et $a l^{24}$ which found no association between hypermobility and sports injury.

The interaction between GJL and variables such as age, gender and ethnicity will make it difficult to ascribe a single cut-off point on the BS. Recent systematic review ${ }^{25}$ recommended a $B S \geq 6$ for children screening and a cut-off of 5 of 9 for adults. Variations in cut-off and methodologies have created differences in the results and conclusions obtained from studies about GJL; this will make interstudy comparisons difficult. Until more data is presented examining these aspects, such analyses should be treated with caution.

We report the following limitations. We have no data on training or competition exposure, which reduces the comparability with other studies reporting injury incidence. The link between type of sport to injury profile is still unclear due to high heterogeneity and small sample size of non-contact sports.

\section{CONCLUSION}

GJL defined by gradient Beighton scoring, plus involvement in contact sports together influence injury risk in youth athletes. Preseason documentation of joint laxity scoring should be considered specifically for contact sports as injury pre-emptive measure.

Acknowledgements The authors would like to acknowledge the contribution of former colleague Dr Jihad Haddad and all other Aspire physiotherapists and thank all the athletes involved in this study. The publication cost was supported by Qatar National Library.

Contributors AR designed and developed the research question and wrote the original version of the manuscript. RW designed the study. AJ was involved in study design. AF supervised and provided expertise with respect to the data analyses. RW, EW, FF, OM and $\mathrm{CH}$ reviewed and provided expertise to the study. All authors have contributed to and edited the manuscript and have approved the final manuscript.

Funding The authors have not declared a specific grant for this research from any funding agency in the public, commercial or not-for-profit sectors.

Competing interests None declared.

Patient consent for publication Obtained.

Ethics approval The study received ethical approval by Shafallah Medical Genetics Center, Qatar.

Provenance and peer review Not commissioned; internally peer reviewed.

Open access This is an open access article distributed in accordance with the Creative Commons Attribution Non Commercial (CC BY-NC 4.0) license, which permits others to distribute, remix, adapt, build upon this work non-commercially, and license their derivative works on different terms, provided the original work is properly cited, appropriate credit is given, any changes made indicated, and the use is non-commercial. See: http://creativecommons.org/licenses/by-nc/4.0/.

\section{REFERENCES}

1. Pacey V, Nicholson LL, Adams RD, et al. Generalized joint hypermobility and risk of lower limb joint injury during sport. Am J Sports Med 2010;38:1487-97.

2. Jackson DW, Jarrett $H$, Bailey $D$, et al. Injury prediction in the young athlete: a preliminary report. Am J Sports Med 1978;6:6-14.

3. Beighton P, Solomon L, Soskolne CL. Articular mobility in an African population. Ann Rheum Dis 1973;32:413-8.

4. Smits-Engelsman B, Klerks M, Kirby A. Beighton score: a valid measure for generalized hypermobility in children. $J$ Pediatr 2011;158:119-23.

5. Collinge R, Simmonds JV, Hypermobility SJV. Hypermobility, injury rate and rehabilitation in a professional football squad--a preliminary study. Phys Ther Sport 2009;10:91-6.

6. Glasgow P, Phillips N, Bleakley C. Optimal loading: key variables and mechanisms. Br J Sports Med 2015;49:278-9.

7. Gannon LM, Bird HA. The quantification of joint laxity in dancers and gymnasts. J Sports Sci 1999;17:743-50.

8. Chahal J, Leiter J, McKee MD, et al. Generalized ligamentous laxity as a predisposing factor for primary traumatic anterior shoulder dislocation. J Shoulder Elbow Surg 2010;19:1238-42. 
9. Sendur OF, Gurer G, Yildirim T, et al. Relationship of $Q$ angle and joint hypermobility and $Q$ angle values in different positions. Clin Rheumatol 2006;25:304-8.

10. Ranalletta M, Bongiovanni S, Suarez F, et al. Do patients with traumatic recurrent anterior shoulder instability have generalized joint laxity? Clin Orthop Relat Res 2012;470:957-60.

11. Birrell FN, Adebajo AO, Hazleman BL, et al. High prevalence of joint laxity in West Africans. Rheumatology 1994;33:56-9.

12. Mueller L, Hildebrandt C, Mueller E, et al. Injuries and illnesses in a cohort of elite youth alpine Ski racers and the influence of biological maturity and relative age: a two-season prospective study. Open Access J Sport Med 2017;8:113-22. Volume.

13. Centenarian AA, The S, Medical B, et al. BMJ Publishing Group Committee (JISC) in the UK. In: This content is also freely available on PubMed central. , 2011: 1, 864-6.

14. Clinch J, Deere K, Sayers A, et al. Epidemiology of generalized joint laxity (hypermobility) in fourteen-year-old children from the UK: a population-based evaluation. Arthritis Rheum 2011;63:2819-27.

15. Covassin T, Cheng G, Nayar S, et al. Epidemiology of overuse and acute injuries among competitive collegiate athletes. 47, 2012: 198-204.

16. Fuller CW, Ekstrand J, Junge A, et al. Consensus statement on injury definitions and data collection procedures in studies of football (soccer) injuries. Scand J Med Sci Sports 2006;16:83-92.

17. Meeuwisse WH, Tyreman $\mathrm{H}$, Hagel $\mathrm{B}$, et al. A dynamic model of etiology in sport injury: the recursive nature of risk and causation. Clinical Journal of Sport Medicine 2007;17:215-9.
18. Timpka T, Alonso JM, Jacobsson J, et al. Injury and illness definitions and data collection procedures for use in epidemiological studies in athletics (track and field): consensus statement. $\mathrm{Br} \mathrm{J}$ Sports Med 2014:48:483-90.

19. Beighton P, Horan F. Orthopaedic aspects of the Ehlers-Danlos syndrome. J Bone Joint Surg Br 1969;51:444-53.

20. Prentice RL, Williams BJ, Peterson A V. On the regression analysis of multivariate failure time data. 63, 1981: 373-9.

21. Konopinski MD, Jones GJ, Johnson MI. The effect of hypermobility on the incidence of injuries in elite-level professional soccer players: a cohort study. Am J Sports Med 2012;40:763-9.

22. Ristolainen $\mathrm{L}$, Heinonen $\mathrm{A}$, Turunen $\mathrm{H}$, et al. Type of sport is related to injury profile: a study on cross country skiers, swimmers, longdistance runners and soccer players. A retrospective 12-month study. Scand J Med Sci Sports 2010;20:384-93.

23. Ullah S, Gabbett TJ, Finch CF. Statistical modelling for recurrent events: an application to sports injuries. Br J Sports Med 2014;48:1287-93.

24. Nathan JA, Davies K, Swaine I. Hypermobility and sports injury. BMJ Open Sport Exerc Med 2018;4:e000366.

25. Juul-Kristensen B, Schmedling K, Rombaut L, et al. Measurement properties of clinical assessment methods for classifying generalized joint hypermobility-A systematic review. Am J Med Genet $C$ Semin Med Genet 2017;175:116-47. 